\title{
$\int^{3}$ \\ POLITEKNIK NEGERI PADANG \\ JuRNAL Taknil $M_{\text {esin }}$ \\ Vol. 14 No.1 (2021) $11-15$ \\ ISSN Media Elektronik: 2655-5670
}

\section{Analisa Pengaruh Bentuk Impingement Plate Terhadap Perpindahan Panas Pada Zona Desuperheating High Pressure Heater}

\author{
Arrad Ghani Safitra ${ }^{1}$, Joke Pratilastiarso ${ }^{2}$, Ibnu Syaifullah Prasetyo ${ }^{3}$, \\ ${ }^{1,2,3}$ Sistem Pembangkit Energi, Departemen Teknik Mekanika dan Energi, Politeknik Elektronika Negeri Surabaya \\ ${ }^{1}$ arradgs@pens.ac.id, ${ }^{2}$ joke@pens.ac.id, ${ }^{3}$ ibnusp10@google.com
}

\begin{abstract}
High Pressure Heater (HPH) are tools that used to improve the efficiency of boiler. HPH utilizes hot steam from turbine extraction as heating medium before entering into the economizer in boiler. In the industry, High Pressure Heater is one of the tools that includes a heat exchanger. To prevent from several problems, some of the industries applying a plate that called impingement plate. This plate placed on the shell side Steam inlet of High Pressure Heater with the function to protect the tube facing the directly the shell side input flow. To determine the effect of adding impingement plates on heat transfer that occurs in the desuperheating zone, a simulation was performed using CFD software with variations of conventional flat plates, 4 plates, and inclined plates. From the simulation results using CFD software it is known that after the addition of the impingement plate, the largest heat transfer value in the desuperheating zone is found in the inclined plate geometry followed by the 4 plate geometry and conventional flat plate, with a q value of 9.54 MW; 7.93 MW; and 4.16 MW, respectively. Then for the inclined plate geometry pressure drop value has a small pressure drop plaing value, which is equal to $30.04 \mathrm{kPa}$.
\end{abstract}

Keywords: high pressure heater, desuperheating zone, impingement Plate, CFD

\begin{abstract}
Abstrak
High Pressure Heater (HPH) merupakan salah satu alat yang berfungsi untuk meningkatkan efisiensi boiler. HPH memanfaatkan uap panas hasil ekstraksi turbin sebagai media pemanas sebelum masuk menuju economizer pada boiler. Di dunia industri, High Pressure Heater (HPH) merupakan salah satu alat yang termasuk alat penukar kalor atau yang diistilahkan dengan Heat Exchanger (HE). Untuk mencegah beberapa kegagalan pada tube, beberapa industri mengaplikasikan plat yang disebut Impinggement Plate pada sisi inlet steam high pressure heater. Plat tersebut diletakkan pada steam inlet sisi shell dari High Pressure Heater dengan fungsi melindungi tube yang menghadap langsung aliran masukan sisi shell. Untuk mengetahui pengaruh penambahan impingement plate terhadap perpindahan panas yang terjadi pada zona desuperheating, maka dilakukan simulasi menggunakan software CFD dengan variasi plat datar konvensional, 4 plat, dan plat inclined. Dari hasil simulasi menggunakan software CFD diketahui bahwa setelah penambahan impingement plate, nilai perpindahan panas terbesar pada zona desuperheating terdapat pada geometri plat inclined lalu diikuti geometri 4 plat dan plat datar konvensional, dengan nilai $q$ sebesar 9,54 MW; 7,93 MW; dan 4,16 MW secara berurutan. Kemudian untuk nilai pressure drop geometri plat inclined memiliki nilai pressure drop plaing kecil, yaitu sebesar 30,04 kPa.
\end{abstract}

Kata kunci: high pressure heater, desuperheating zone, impingement plate, CFD

\section{Pendahuluan}

Pembangkit Listrik Tenaga Uap (PLTU) merupakan salah satu pembangkit listrik yang banyak digunakan di Indonesia. Proses pembangkitan energi listrik pada PLTU dipengaruhi oleh beberapa komponen utamanya, diantaranya boiler, kondensor, turbin dan generator.
Pada prosesnya, air masuk menuju boiler untuk dipanaskan sampai menjadi uap kering. Uap kering tersebut digunakan untuk menggerakkan turbin dan generator sehingga menghasilkan energi listrik.

High Pressure Heater $(H P H)$ merupakan salah satu alat yang berfungsi untuk meningkatkan efisiensi boiler. HPH memanfaatkan uap panas hasil ekstraksi turbin sebagai media pemanas sebelum 
masuk menuju economizer pada boiler. Di dunia industri, High Pressure Heater (HPH) merupakan salah satu alat yang termasuk alat penukar kalor atau yang diistilahkan dengan Heat Exchanger (HE). Heat exchanger merupakan sebuah alat yang berfungsi sebagai penukar kalor antara dua fluida yang memiliki temperatur berbeda dan dipisahkan oleh dinding solid [1]. Beberapa tipe heat exchanger yang sering digunakan diantaranya Shell and Tube Heat Exchanger dan Double Pipe Heat Exchanger.

Untuk mencegah beberapa permasalahan akibat inlet steam yang menabrak tube, beberapa industri mengaplikasikan plat yang disebut Impinggement Plate. Plat tersebut diletakkan pada steam inlet sisi shell dari High Pressure Heater dengan fungsi melindungi tube yang menghadap langsung aliran masukan sisi shell [2]. Dengan diaplikasikannya plat tersebut dapat mengurangi dampak dari penipisan dinding tube akibat aliran inlet steam High Pressure Heater yang tinggi.

Agus Ari Wibowo, 2011 melakukan penelitian terhadap variasi bentuk impingement plate. Pada penelitian tersebut digunakan software Fluent 6.3.26 secara dua dimensi. Simulasi dilakukan dengan mengasumsikan bahwa aliran fluida setelah malalui nozzle akan mengalir melalaui impingement plate yang dikondisikan sebagai inlet untuk mengetahui pengaruh perubahan sudut inlet dari impingement plate sehingga didapatkan laju perpindahan panas yang optimal. Sudut impingement plate divariasikan menjadi 3 yaitu bentuk 26, 70 dan 120. Susunan tube yang disimulasikan adalah tube bank staggered dengan jumlah tube 1670 buah dan pitch arrangement 60$22 \mathrm{~mm}$ dengan diameter tube luar $15875 \mathrm{~mm}$ dan diameter tube dalam $11659 \mathrm{~mm}$. Kondisi masukkan pada inlet berupa mass flow sebesar $8.696 \mathrm{~kg} / \mathrm{s}$. Distribusi temperatur dihasilkan dengan mengkondisikan dinding tube bagian dalam sebagai konjugate dengan nilai koefisien konveksi 19,06232 Wm2.K pada temperatur free stream sebesar $43.958 \mathrm{~K}$. Pada penelitian kali tersebut diperoleh bahwa perpindahan panas terbaik terjadi pada inlet 70 . Variasi inlet 26, 70 dan 120 apabila dibandingkan menghasilkan penurunan laju perpindahan panas sebesar $4.885 .739,654 \mathrm{~W}$ untuk inlet 26, 5.101.617,796 W untuk inlet 70 dan $5.060 .968,212 \mathrm{~W}$ untuk inlet 120. Sedangkan dari ketiga variasi inlet didapatkan pressure drop terkecil terjadi pada inlet $120(68,995 \mathrm{~Pa})$ diikuti inlet $26(109,484 \mathrm{~Pa})$ dan inlet $70(110,006 \mathrm{~Pa})$. Apabila ditinjau dari laju perpindahan panas dan pressure drop yang dihasilkan maka dapat disimpulkan dari ketiga variasi inlet maka inlet 120 menghasilkan performa yang paling baik.

S.S. Al-Anizi dan A.M. Al-Otaibi, 2007 melakukan penelitian dengan memodifikasi bentuk impingement plate. Hal ini dilakukan akibat terbentuknya proses fouling dibawah impingement plate. Penumpukan fouling tersebut dapat menyebabkan korosi dan peningkatan temperatur permukaan sehingga menyebabkan kegagalan. Pada penelitian tersebut plat dimodifikasi menjadi plat ganda dengan offset holes, yang disebut Double Perforated Impingment Plate (DPIP). Plat DPIP tersebut menghancurkan vortisitas yang terbentuk dibelakang plat konvensional dan menghentikan proses pembentukan fouling. Setelah melakukan analisis dengan software CFD dari penelitian tersebut disimpulkan dengan plat DPIP memiliki Fluid Dynamic yang lebih baik dibandingkan dengan plat konvensional. Hal ini disebabkan adanya celah pada DPIP sehingga terdapat aliran kecil yang menyebabkan penumpukan fouling berkurang.

R.S. Maurya dan S. Singh, 2017 melakukan penelitian mengenai impingement plate untuk mengetahui struktur aliran yang terbentuk pada berbagai desain impingement plate yang berbeda menggunakan software CFD secara 2D. Parameter pada penelitian tersebut diantaranya tempat, ukuran dan susunan dari impingement plate yang memberikan beberapa informasi untuk mengetahui lokasi dan ukuran ideal yang dibutuhkan. Kemudian dilakukan penelitian efek dari geometri pada impingement plate. Pada penelitian tersebut digunakan 9 variasi geometri plat. Dari hasil hasil simulasi menggunakan CFD terlihat pada Grafik 2 pressure head loss dan kinetic energy loss terkecil terdapat pada variasi plat inclined.

Pada penelitian ini simulasi digunakan untuk mengamati dampak dari bentuk impingement plate yang berbeda dengan menggunakan Computational Fluid Dynamics (CFD), dimana bentuk impingement plate yang diambil berbentuk plat datar, empat plat, dan plat inclined. Plat tersebut dipilih dikarenakan memiliki celah yang bisa meminimalisir area stagnan [3]. Kemudian diharapkan dari simulasi ini dapat mengamati perpindahan panas yang terjadi pada High Pressure Heater dengan bentuk impingement plate yang berbeda.

\section{Metode Penelitian}

Pada studi numerik dengan metode CFD, tahap pertama yaitu pre-processing terdiri dari pembuatan geometri. Pada penelitian ini digunakan geometri High Pressure Heater pada bagian zona desuperheating secara 2D dengan data operasi dari PLTU. Perancangan awal pemodelan zona desuperheating dilakukan tanpa adanya impingement plate. Kemudian variasi geometri impingement plate digunakan tiga jenis bentuk plat, yaitu plat datar konvensional,plat dengan 4 bagian, dan plat dengan bentuk inclined. Berikut gambar 1 merupakan geometri zona desuperheating yang telah digambarkan. 

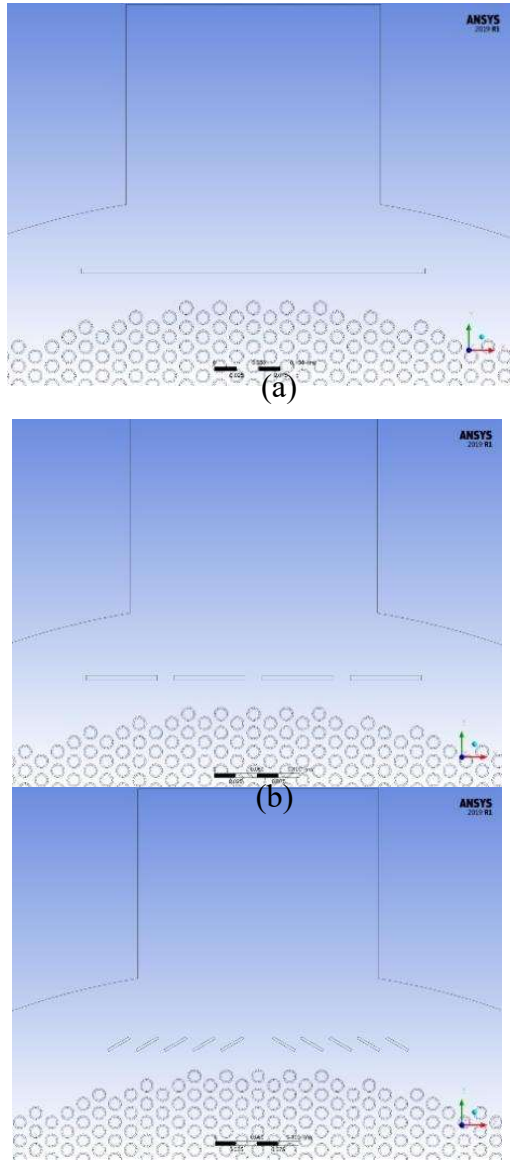

Gambar 1. Geometri Impingement Plate a) Plat Datar,Konvensional b) 4 Plat, c) Plat Inclined

Kemudian setelah itu dilakukan meshing. Meshing dilakukan untuk membuat domain menjadi beberapa sel yang lebih kecil untuk mempermudah proses komputasi. Untuk mengetahui bahwa hasil komputasi yang telah dilakukan sudah baik, maka perlu dilakukan grid imodependence. Tabel 1 merupakan hasil proses dari grid independence yang telah dilakukan. Dari tabel 1, dipihlah element 157.836 dikarenakan eror temperatur output dan element yang dihasilkan kecil. Kemudian dari element tersebut memiliki kualitas yang bagus, dimana skewness bernilai 0,203 dan orthogonal bernilai 0,947 .

\begin{tabular}{lc}
\multicolumn{2}{c}{ Tabel 1. Grid Independence } \\
\hline Element & Temperatur (K) \\
\hline 157.836 & 553,4 \\
\hline 327.959 & 553,9209 \\
\hline 582.679 & 550,2253 \\
\hline 697.992 & 550,696 \\
\hline
\end{tabular}

Kemudian masuk ketahap processing digunakan model viscous steady state dengan persamaan standard $\mathrm{k}-\varepsilon$ dan mengatur kondisi inlet sebagai mass flow inlet $(31,905 \mathrm{~kg} / \mathrm{s})$ sedangkan untuk outflow diatur sebagai outflow.

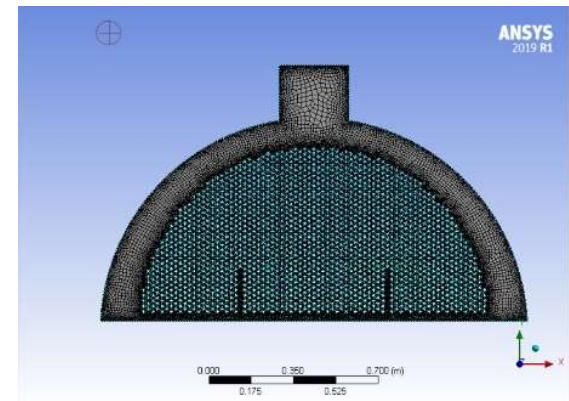

Gambar 2. Meshing pada Zona Desuperheating Tanpa Penambahan Plat

Pada proses postprocessing, dilakukan pengambilan data dan juga kontur.

\section{Hasil dan Pembahasan}

Untuk mengetahui performa dari heat exchanger, diperlukan juga untuk menghubungkan laju perpindahan panas dengan data seperti temperatur fluida pada inlet maupun outlet. Perhitungan yang dilakukan berdasarkan buku Fundamental of Heat and Mass Transfer [1]. Dengan mengabaikan energi potensial dan energi kinetik, maka persamaan laju perpindahan panas dinyatakan seperti berikut.

$q=\dot{\mathrm{m}}_{h}\left(i_{h, i}-i \quad h, o\right.$

Dengan $\dot{m}$ merupakan laju alir masa dan i merupakan entalpi fluida. Kemudian karena pada simulasi tidak terjadi perubahan fasa dan nilai $C_{p}$ adalah konstan, maka persamaan laju perpindahan panas dinyatakan sebagai berikut.

$$
q=\dot{\mathrm{m}}_{h} \cdot C_{p}\left(T_{h, i}-T_{h, o}\right)
$$

Tabel 2. Hasil Simulasi

\begin{tabular}{cccccc}
\hline $\begin{array}{c}\text { Jenis } \\
\begin{array}{c}\text { Impingement } \\
\text { Plate }\end{array}\end{array}$ & $\begin{array}{c}\dot{\mathrm{m}} \\
(\mathrm{kg} / \mathrm{s})\end{array}$ & $\begin{array}{c}\mathrm{Cp}(\mathrm{J} / \mathrm{kg} \\
\mathrm{K})\end{array}$ & $\mathrm{Ti}(\mathrm{K})$ & $\mathrm{To}(\mathrm{K})$ & $\Delta \mathrm{T}(\mathrm{K})$ \\
\hline Plat Datar & 31,905 & $4.737,816$ & 622,82 & 595,264 & 27,556 \\
4 Plat & 31,905 & $4.737,816$ & 622,82 & 570,388 & 52,432 \\
Plat Inclined & 31,905 & $4.737,816$ & 622,82 & 559,665 & 63,155 \\
\hline
\end{tabular}

\begin{tabular}{ccr}
\multicolumn{3}{c}{ Tabel 3. Hasil Perhitungan } \\
\hline Jenis Plat & $\Delta \mathrm{P}(\mathrm{Pa})$ & $\mathrm{q}(\mathrm{W})$ \\
\hline Plat Datar & $134.476,8$ & $4.165 .365,5$ \\
4 Plat & $78.966,36$ & $7.925 .622,1$ \\
Plat Inclined & $30.040,16$ & 9.546 .511 \\
\hline
\end{tabular}


Pada Tabel 2 dapat dilihat hasil simulasi dan di Tabel 3 disajikan data hasil perhitungan, terlihat bahwa dengan bentuk impingement plate yang berbeda menyebabkan nilai laju perpindahan panas yang berbeda pula, dimana dengan penambahan impingement plate berbentuk plat inclined memiliki nilai $q$ tebesar diikuti dengan bentuk 4 plat, sedangkan plat datar konvensional menghasilkan nilai $\boldsymbol{q}$ terkecil. Hal tersebut dikarenakan pada penggunaan impingement plate dengan plat datar konvensional aliran uap ektraksi akan terhalang sehingga tidak langsung menabrak susunan tube baris pertama dan mengurangi kontak uap ektraksi dengan tube. Dengan berkurangnya kontak antara uap ektraksi dengan tube maka nilai $\Delta \mathrm{T}$ akan berkurang. Hal ini sesuai dengan teori, dimana nilai laju alir dan juga nilai $\boldsymbol{C}_{\boldsymbol{p}}$ yang konstan, maka nilai q bergantung pada beda nilai temperatur $(\Delta \mathrm{T})$. Maka semakin besar nilai $\Delta \mathrm{T}$ menyebabkan nilai $\boldsymbol{q}$ yang dihasilkan semakin meningkat, dan juga sebaliknya ketika semakin kecil nilai $\Delta \mathrm{T}$ menyebabkan nilai $\boldsymbol{q}$ yang dihasilkan semakin kecil.

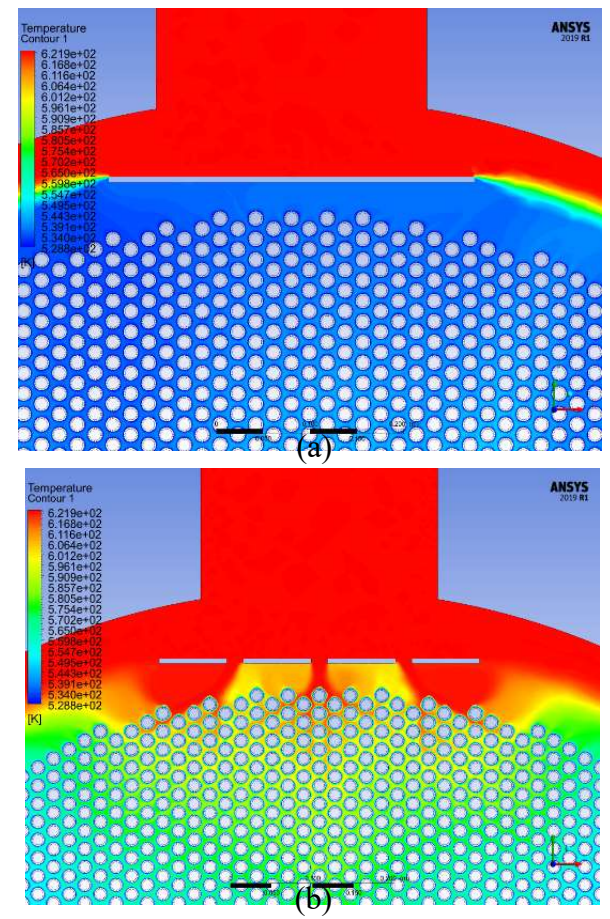

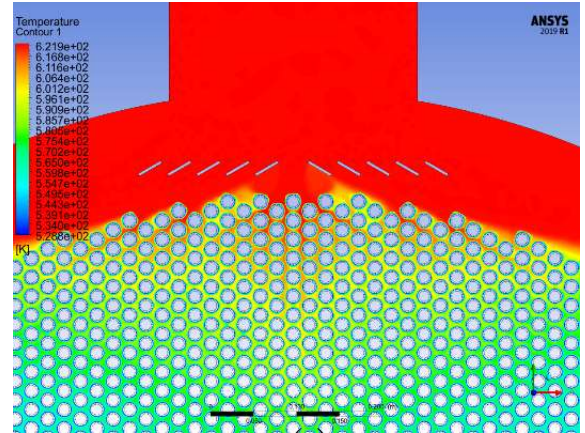

(c)

Gambar 3. Kontur Temperatur a) Plat Datar b) 4 Plat c) Plat Inclined

Pada Gambar 3 menunjukkan kontur temperatur pada geometri zona desuperheating dengan plat datar, 4 plat, dan plat inclined. Pada gambar terlihat bahwa kontur temperatur yang dihasilkan dengan impingement plate berbentuk plat datar terdapat perbedaan dimana pada kontur dengan impingement plate berbentuk plat datar gradasi di bawah plat cenderung berwarna kebiruan. Hal ini menandakan kontak antara uap ektraksi dengan tube tidak mencapai tube bagian bawah plat sehingga perpindahan panas yang dihasilkan berkurang. Hal ini dibuktikan dengan temperatur outlet dimana pada temperatur outlet pada penambahan impingement plate berbentuk plat datar sebesar $595,264 \mathrm{~K}$, sedangkan pada tanpa bentuk 4 plat dan plat inclined temperatur outlet sebesar $570,388 \mathrm{~K}$ dan 559,665 K.

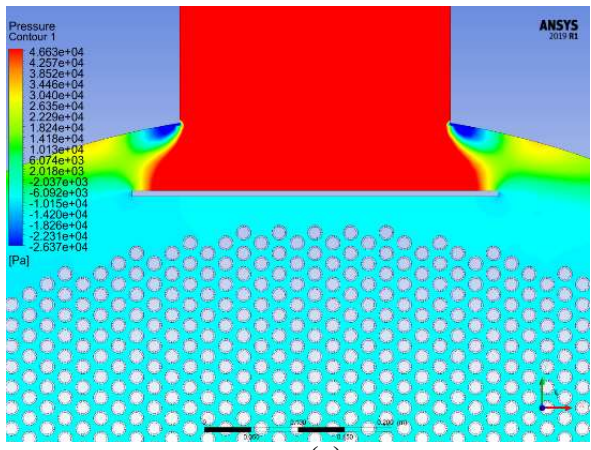

(a)

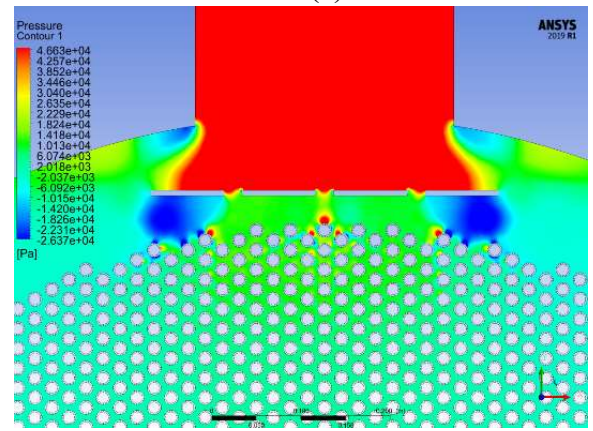

(b) 


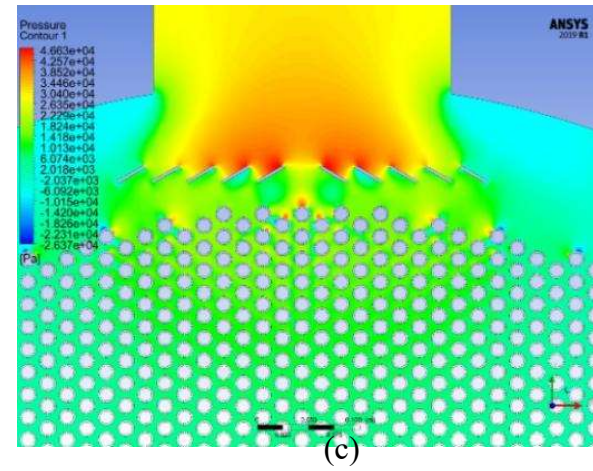

Gambar 4. Kontur Tekanan a) Plat Datar b) 4 Plat c) Plat inclined

Gambar 4 menunjukkan kontur tekanan yang terjadi saat ditambahkan impingement plate. Pada Gambar 4 terlihat bahwa tekanan terbesar terjadi pada impingement plate yang ditunjukkan oleh warna orange-merah. Hal ini dikarenakan impingement plate terletak tepat di bawah inlet, sehingga bagian yang langsung mengenai uap ektraksi adalah impingement plate. Namun pada geometri plat datar, pada bagian bawah impingement plate terdapat tekanan yang rendah yang ditunjukkan oleh warna kebiruan jika dibandingkan dengan geometri 4 plat dan plat inclined. Hal ini disebabkan aliran uap ektraksi turbin yang mengalir ke bagian sisi antara dinding high pressure heater dan tube. Kemudian dari tabel 3 diketahui bahwa pressure drop terendah terdapat pada bentuk geometri plat inclined, diikuti dengan geometri 4 plat dan pressure drop terbesar terdapat pada geometri plat datar.

\section{Kesimpulan}

Dari hasil penelitian yang telah dilakukan dapat disimpulkan

1. Secara laju perpindahan panas penggunaan impingement plate dengan geometri plat inclined memiliki performa yang paling baik dengan nilai $q$ paling besar, yaitu 4,16 MW.

2. Kemudian berdasarkan pressure drop penggunaan impingement plate dengan geometri plat inclined memiliki nilai yang paling kecil, yaitu sebesar 30,04 $\mathrm{kPa}$.

\section{Daftar Rujukan}

[1] Incropera, DeWitt, Bergman, and Lavine, 2007. Fundamental of Heat and Mass Transfer. 6th Edition.USA: John Wiley \& Sons Inc.

[2] S. S. Al-Anizi and A. M. Al-Otaibi, 2009. Heat Transf. Eng. Double perforated impingement plate in shell-and-tube heat exchanger, vol. 30, no. 10-11, 885-894.

[3] R. S. Maurya and S. Singh, 2017. J. Therm. Eng. Numerical investigation of isothermal flow around impingement plates in a shell and tube exchanger, vol. 3, no. 5, 1442-1452.

[4] Wibowo, Agus Ari, 2011. Studi Numerik 2D Pengaruh Sudut Impingement Terhadap Karakteristik Aliran dan Perpindahan Panas Pada Zona Desuperheating High
Pressure Heater. Surabaya: Institut Teknologi Sepuluh Nopember, Tidak Dipublikasikan.

[5] Wijnarko, Nadia P, 2017. Re-design High Pressure Heater (HPH) 5 Unit 1 di PT. PJB UP. Gresik Menggunakan Analisis Termodinamika dan Perpindahan Panas. Surabaya: Tugas Akhir Institut Teknologi Sepuluh Nopember. 